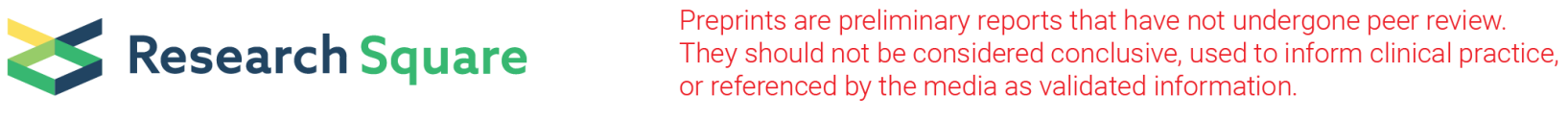

\title{
Use-wear Traces and Plant Micro-remain Analysis Reveal the Function of Perforated Shells From the Xianrendong and Diaotonghuan Sites in the Middle Reaches of the Yangtze River, China
}

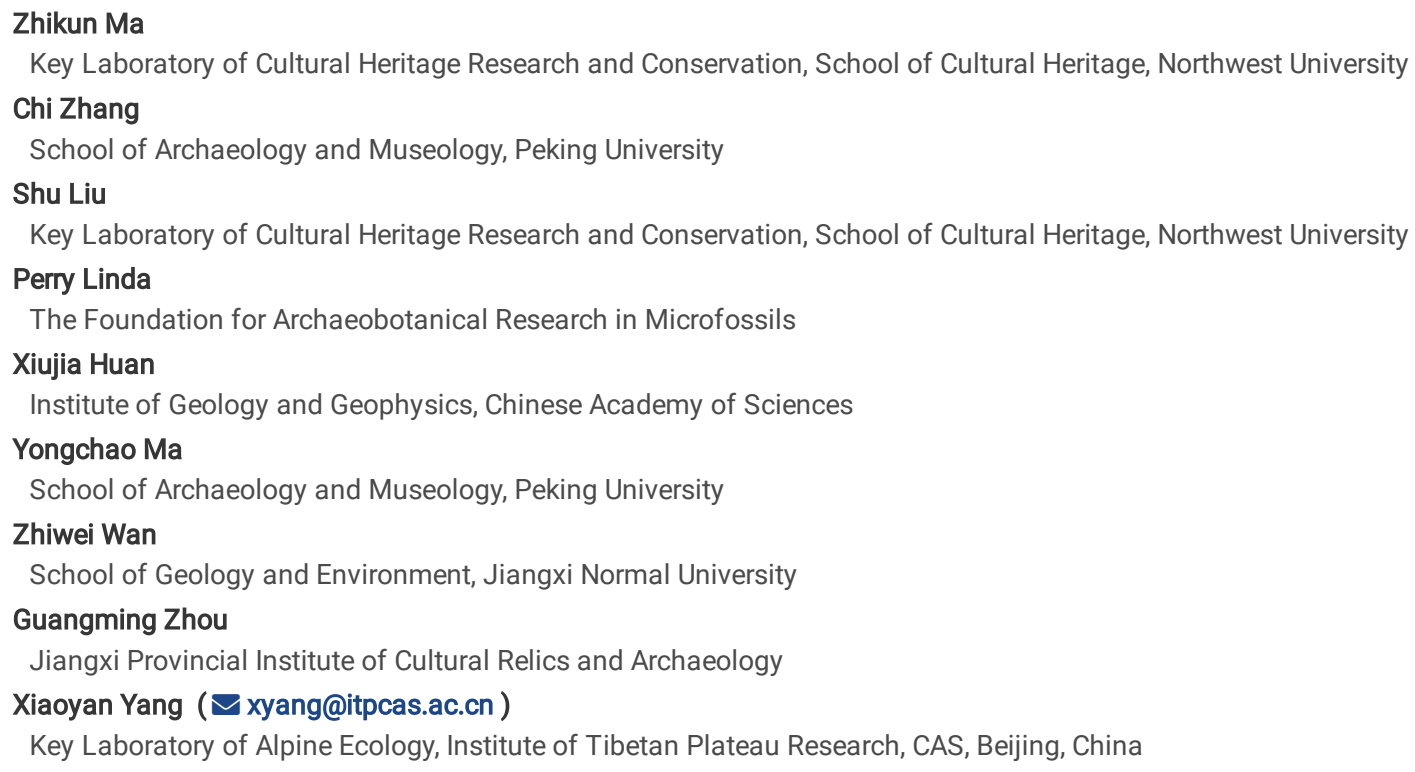




\section{Abstract}

Shell remains are common cultural relics recovered from the late Paleolithic to the historical-age sites in China. Archaeological evidence shows that the number of perforated shells gradually increased at the transition from the Paleolithic to Neolithic age, a time period that coincides with the beginning of farming activities. Usage traces and plant residues from prehistoric perforated shells are often used to interpret tool function. In this study, we analyzed usewear traces and recovered ancient starches and phytoliths from both the used edges and unused backs of twelve perforated shells from the Xianrendong and Diaotonghuan sites $(30,000-12,000 \mathrm{cal}$. Y BP). These sites are well-known for the earliest pottery and the earliest cultivated rice micro-remains in the world. We found that: (1) all the twelve shells had scars and use wear, and the use traces occurred on the used edges; (2) an assemblage of 83 identifiable starch grains were recovered from the twelve perforated shells, including remains of acorns, Panicoideae and the tribe Triticeae, tubers and roots; ( 3 ) only six phytoliths from the stems and leaves of grass taxa including Panicoideae and Bambusoideae were recovered from four shells. The meta-analysis of the usewear and plant micro-remain analysis indicate that the functions of perforated shells were nearly identical from the late Paleolithic to early Neolithic periods. These functions include processing, harvesting or cutting grasses from the Panicoideae, Bambusoideae, and the tribe Triticeae, processing acorns or/and their starchy products, and digging and scraping tubers and roots. The digging and scraping of tubers and roots increased in intensity with the increase in rice cultivation during the period between 20,000 and 12,000 cal. Y BP.

\section{Introduction}

Shell remains, which have been recovered from the Paleolithic to historical periods, can provide us with a great deal of information about human behavior, including agricultural productivity and processing1,2. Based on the archaeological data from KsarAkil site in Southwest Asia (37,000 BP)3, Trinil site (540,000430,000 BP)4 and Colo site (32,000-28,000 BP) 5 in Southeast Asia, Xiaogushan site (40,000-20,000 BP)6, Sanjiadian site (late Middle Pleistocene)7, Shizitan site (29,000-13,000 BP)8, Longwangchan site (20,000-15,000 BP)9, Xianrendong site, Diaotonghuan site (about 30,000 12,000 cal. Y BP)10 and Miaoyan site (18,000-12,000 cal. Y BP)11 in East Asia, the number and proportion of perforated shells gradually increased at the transition from the Paleolithic to the Neolithic Age12.

Currently, combining methods from ethnoarchaeology and typology, most scholars proposed that shell remains, especially perforated shells, were mainly used as tools for cutting, scraping, harvesting, and tilling1-3,5,13-15. Some scholars have inferred that perforated shells were also used as ornaments 15,16 , tools for pottery making17, tanning2, implements for religious worship15 or spoons (or similar tools) 16 . These conclusions, however, were based upon observations and analogy rather than direct evidence.

During the use of shell remains to process plant foods, use-wear could be created, and proteins, tartaric acid and plant micro-remains including starch grains and/or phytoliths could be captured in the cracks and crevices on the used edges18-22. These marks and residues left on the surfaces of the archaeological shells provide evidence for the study on the functions of the ancient artifacts. For example, an application of use-wear analysis led some scholars to conclude that shells were used for cutting bovid bones23. Starches from breadfruit (Artocarpusaltilis), kava (Piper methysticum), taro (Colocasia esculenta), and yam (Dioscorea) extracted from the surfaces of 23 shell from the Marquesas Islands, demonstrated the multifunctionality of these shells24. Thus, analyses of usage traces and plant micro-remains are effective methods for exploring the functions of shell artifacts. Further, it has been suggested that an ideal approach to study the functions of the cultural relics is using a combination of techniques, use wear and residue analyses 25.

The Xianrendong and Diaotonghuan sites are situated in Jiangxi Province in the middle reaches of the Yangtze River regions, China, and they have provided evidence documenting the origins of rice farming during the late Paleolithic and Neolithic periods26. Artifact assemblages from these two sites include the earliest pottery sherds in the world27, and a large number of stone tools and animal remains, including shell remains 10 . In 2012, we had conducted starch grain analysis on two perforated shell artifacts, and tentatively identified the grass tribes Triticeae and Paniceae from residues, as well as some starches derived from the stems of grass plants28. Based on the starches from plant stems recovered from these two shells, we speculated that harvesting was one of the functions of the perforated shells at Xianrendong and Diaotonghuan sites. Because the method used in the previous study was relatively simple with a small number of samples, here we expanded our materials to twelve perforated shells excavated from the two sites with a combination analyses of use wear and plant micro-remains, aiming to recover objective evidence for the functions. The data allow us to discuss the roles these shell artifacts played during this important transitional period from pre-domestication to the domestication of rice (Oryza sativa).

The Xianrendong and Diaotonghuan sites are located in northern Jiangxi Province, China (Fig. $1 \mathrm{~A})$. The AMS ${ }^{14} \mathrm{C}$ dates for both sites were derived from charcoal, carbonized seeds, and bones, and placed the occupations at 30,000 12,000 cal. Y BP27. The Xianrendong site $\left(28^{\circ} 44^{\prime} 9.72 " \mathrm{~N}, 117^{\circ} 10^{\prime} 23.70^{\prime \prime} \mathrm{E} ; \mathrm{Fig}\right.$. $1 \mathrm{~A}$ ) is a cave facing southeast with a $3 \mathrm{~m}$ thick cultural deposit. Strata represent five distinct and sequential cultural occupations, mainly during the late Paleolithic and early Neolithic periods, a few from the late Neolithic, the Shang and Zhou Dynasties, and a modern disturbance layer. The Diaotonghuan site $\left(28^{\circ} 44^{\prime} 9.62^{\prime \prime} \mathrm{N}, 117^{\circ} 10^{\prime} 23.35^{\prime \prime} \mathrm{E} ;\right.$ Fig. $\left.1 \mathrm{~A}\right)$ is a passthrough rock-shelter, $800 \mathrm{~m}$ west of the Xianrendong site, with a $5 \mathrm{~m}$ thick cultural deposit.

From the 1960 s to 1990 s, the sites were excavated during five seasons. Numerous stone tools $(n>600)$, bone artifacts $(n>240)$, and shell remains $(n>290)$ were excavated ${ }^{10}$. The excavated shell remains have one or two drilled holes, or none, occasionally. In terms of the stratigraphic sediments and artifact types, the two sites were considered to be occupied at nearly the same time ${ }^{10,29}$.

\section{Results}

Results of the use wear analysis. Scars, use-wear marks, and perforation marks in varying sizes were observed on all the twelve perforated shells from the Xianrendong and Diaotonghuan sites (Fig. 1B囚- , Fig. 2a, b). Further, transverse and diagonal striations were detected on the used edges, the thinner side (which also means the used edge) with white luster, of all the perforated shells (Fig. 2c-h). 
Results of starch grain analysis. More than 83 starch grains were recovered from 24 subsamples of the twelve perforated shells, and they can be divided into 5 categories (Table 1).

Type A - the Fagaceae: The common features of type A grains $(n=4)$ were their various ovate shapes. Some type A grains were aggregated together in a cluster. When the grains were rotated, they still retained their ovate shapes. The properties of type A starches were consistent with the morphological characteristics of Fagaceae, therefore, we identified the type A grains as a type of Fagaceae. Based on the differences in the size of their diameters, surface morphologies, and fissure types, the type A grains could be divided into two subtypes: type A1 grains (Fig. 2i, j) with lengths $15.4 \mu \mathrm{m}$ and $18.7 \mu \mathrm{m}$, which are consistent with the features of the grains of Cyclobalanopsis aggregated together; type A2 grains (Fig. 2k, I) with a smooth surface, regular oval shape, and smaller particle sizes (diameter lengths of $11.0 \mu \mathrm{m}$ and $14.7 \mu \mathrm{m}$ ), which are consistent with the features of the disarticulated grains of Cyclobalanopsis.

Type B - the Poaceae: Thirty-nine starch grains were polyhedral in shape with a centric hilum and lacked the presence of lamellae; most grains also had deeply crossed or winged fissures. Their size range and mean diameter were 7.3-25.9 $\mu \mathrm{m}$ and $15.8 \pm 2.4 \mu \mathrm{m}$, respectively. Modern reference collections show that starch grains from the pith of Sorghum, Zea, Setaria, Panicum, and Coix are similar to the type B starch grains, as characterized by their pressure facets. In general, it is understood that the genera Sorghum and Zea were initially domesticated in Africa and America about 9,000 years ago, respectively30,31 whereas the genera Setaria and Panicum were utilized and domesticated in China about 23,000 and 10,000 years ago, respectively32,33. The morphological characteristics and size range (the length of diameter, 5-20 $\mu \mathrm{m}$ ) of starches from the genera Setaria and Panicum were consistent with the ancient starch grains extracted from the shell artifacts. In our previous study, after the starch grains derived from the seeds of 31 modern millet samples were analyzed, a system of classification was established to define the diagnostic morphological characteristics of the starch grains, including those of wild millets, which are small particles (the length is usually $10-14 \mu \mathrm{m}$ ) with wrinkled surfaces and rough edges. Only domesticated foxtail millets (Setaria italica) have starch grains measuring $>14.0 \mu \mathrm{m} 34$. Further, polyhedral and spherical starches (range, 20-32.3 $\mu \mathrm{m}$ ) in millet stems and lenticular starches (range, 9.7-38.4 $\mu \mathrm{m}$ ) in millet leaves were found in experimental harvesting20,22. Starches from Coix such as Job's tears (Coixchinensis) are polyhedral in shape and exhibit linear-, V-, Yshaped or radiated fissures (range, 5.3-29.2 $\mu \mathrm{m}$ ). In previous studies, a zig-zag arm on the extinction cross and an eccentric hilum have been observed as diagnostic features in the seed starch of Job's tears35. Some ancient starches in type B are similar to those from the seeds of Coix. Therefore, we divided thirty-nine type B starch grains into three groups: type B1 starch grains, those of wild millets from genera of Setaria and Panicum, which are small particles ( $n=19$; range, 7.3-9.7 $\mu \mathrm{m}$; mean size, $8.7 \pm 1.8 \mu \mathrm{m}$ ) with wrinkled surfaces and rough edges (Fig. $2 \mathrm{~m}, \mathrm{n}$ ); type B2 starch grains, those from Coix, which are polyhedral in shape with a smooth surface, a zig-zag arm on the extinction cross, and an eccentric hilum $(n=13,20-25.9 \mu \mathrm{m}, 24.5 \pm 3.1 \mu \mathrm{m}$; Fig. 20 , p); the remaining 7 starch grains (type B3 starch grains, $n=7,8.5 \sim 19.9 \mu \mathrm{m}, 18.9 \pm 2.7 \mu \mathrm{m}$; Fig. 2q, r), which may contain grains from ordinary seeds, stems of millets, and Coix plants (Fig. 2s, t). In summary, the type B starch grains are derived from grasses in the Panicoideae, probably genera from Setaria, Panicum and Coix plants, including some starches from stems of the three genera.

Type C - geophytes: nineteen starches were characterized by a larger granule size, an eccentric hilum, irregular triangular or oval shape, and bent extinction crosses (range, 9.0-26.5 $\mu \mathrm{m}$; mean size, $16.2 \pm 4.8 \mu \mathrm{m}$ ). These starches show strong similarities in morphology and size with those of the roots and tubers in our modern samples36. Based on the morphological characteristics of type $\mathrm{C}$ starch grains, they were categorized as polyhedral type $\mathrm{C} 1$ starch grains (Fig. $2 \mathrm{u}$, v) with a slightly eccentric hilum, vertical or slightly bent extinction crosses, lamellae, and fissuring, which occasionally appears on the large grains ( $n=11$; range, 9.0-22.5 $\mu \mathrm{m}$; mean size, $15.7 \pm 5.2 \mu \mathrm{m}$ ), oval type $\mathrm{C} 2$ starch grains (Fig. $2 \mathrm{w}, \mathrm{x}$ ) with an irregular oval shape, an extremely eccentric hilum, and craters on the surface ( $n=2$, size $24.8 \mu \mathrm{m}$ and $25.7 \mu \mathrm{m})$; and the common hemispherical type C3 starch grains (Fig. $2 \mathrm{y}$, z) with a slightly eccentric hilum, slightly bent extinction crosses, and a few compound grains ( $n=6$; range, $17.8-26.5 \mu \mathrm{m}$; mean size, $14.1 \pm 4.2 \mu \mathrm{m})$. Type $\mathrm{C} 1$ and a portion of type $\mathrm{C} 3$ starch grains are similar to those derived from taro corms, which have slightly eccentric hila, vertical or slightly bent extinction crosses, some compound grains, and large grains occasionally have lamellae and fissuring. Other root and tuber plants, however, also contain a certain number of hemispherical starch grains, so type C3 starch grains may also be derived from some other root and tuber plants. Type $\mathrm{C} 2$ starch grains show strong similarities in morphology and size with those of Dioscorea in the modern database. In summary, Type C starch grains are probably derived from root and tuber plants, including taros and Dioscorea.

Type D - the Poaceae: Seventeen starch grains had an irregular lenticular shape (such as an ellipse or a semicircle) with a centric hilum and craters on the surface (range, 14.3-38.0 $\mu \mathrm{m}$; mean size, $24.1 \pm 5.6 \mu \mathrm{m}$; Fig. 2A, B). The extinction crosses appeared either as " $X$ " or " $\nabla$ " in shape. The starch grains were olivary and had an equatorial groove when rotated (Fig. 2C, D). The type D grains were similar to the starch grains of the tribe Triticeae studied by Yang and Perry37, and thus we inferred the type D grains were from the tribe Triticeae. In addition, three starches (Fig. 2E, F) were similar to the starch grains collected from the leaves of Panicoideae, Pooideae, and Phragmites22. Therefore, we inferred that the type D grains were from the tribe Triticeae and may also contain a certain number of starches from the stems and leaves of Panicoideae, Pooideae, and Phragmites.

Type E (Fig. 2G, H) - unidentifiable: The remaining 4 starches that could not be identified because of the damage or an absence of identifiable characteristics are grouped into Type $\mathrm{E}$.

Results of phytolith analysis. According to the references for phytolith taxa in China38,39, specific phytolith types are predominantly, although not restricted to, those produced by certain plants. The most commonly occurring forms include bilobate, saddle, rondel, acicular hair cells, smooth elongate, square and trapeziform sinuate phytoliths from stems and leaves of the Poaceae40; bilobates from Panicoideae41; and long-saddle forms from Bambusoideae42.

Only six phytoliths were retrieved from the study samples (Table 1), and they were all from stems and leaves of the Poaceae. One smooth elongate (Fig. 2l) and one acicular hair cell (Fig. 2J) were recovered from residues on the shell 99WX-1746 E10N12 Z: $₫ A \rrbracket$ from the Xianrendong site. Four phytoliths were recovered from three perforated shells in the Diaotonghuan site, including one bilobate of the Panicoideae from shell 93WW-2265 W3S1 Z:L (Fig. 2K), one long-saddle of the Bambusoideae from 95WW-3452 W3NO Z:H (Fig. 2L), and two squares from 95WW-3353 W2S3 Z:G and 95WW-3452 W3N0 Z:H (Fig. 2M).

No starches and phytoliths were extracted from the dust samples in the storeroom where the twelve shells were stored. 


\section{Discussion}

Starch grains and phytoliths were not extracted from the dust samples from the storerooms, thus strongly suggesting the possibility of the shell samples being contaminated in storage.

Functions of perforated shells deduced from use-wear marks. Based on the thin and long lateral and oblique striations left on the surfaces of the twelve perforated shells from the Xianrendong and Diaotonghuan sites (Fig. 2c-h), it appears that the main direction of motion during use was parallel to the edge or in a direction that presents a consistent angle with the edge, and all shells had scars caused by stress cracking during use (Fig. 1B囚- $\rrbracket$ ). These usage traces are consistent with the wear features of cutting, mowing, scraping, slicing, planting, and digging obtained in many simulation experiments $22,43,44$. We therefore believe the perforated shells analyzed in this study were likely used for cutting, digging, and scraping. Further, we observed that each shell was perforated with holes in varied sizes (Fig. 2a, b). Using methods of typology and ethno-archaeology, scholars have hypothesized that the drilled holes on the shell may have been used to tie the tool with strings of different thicknesses or embed it in wood implements of different sizes, which would be convenient to grasp and use 1 .

Functions of perforated shells deduced from plant micro-remains. The function of cutting and/or harvesting: If the shells were used to harvest crops as tools, the edges would be in contact with the stems and leaves of the crops. First, starches and phytoliths from stems and leaves could be left on the surface of tools; second, the numbers of starch grains and phytoliths should be greater than what was collected from the unused tools in a previous study22,37.

In this study, six phytoliths from stems and leaves in the Poaceae were recovered from the used edges of four perforated shells (Table 1), indicating phytoliths are related to the use of shells. There are 83 starch grains from twelve perforated shells in total. Excluding the shells of which unused edges yield more starches than the used edges, leaves only 3 perforated shells to consider, 99WX-1746 E10N12Z:『A囚, 95WW-3452 W3N0 Z: H95, and 93WW-2265 W3S1 Z: L. The evidence from both the starches and phytoliths supports the hypothesis that these three perforated shells were used to harvest or cut plants at the Xianrendong and Diaotonghuan sites, as some scholars proposed1-3,5,13. As for the types of the plants that harvested or cut by the shells, three starches from stems and leaves of the grasses in the Panicoideae (type B3, $n=2$ ) and Poaceae (Type $D, n=1$ ) (Table 1), five phytoliths from stems and leaves of the Poaceae (Table 1) including Panicoideae $(n=1)$ and Bambusoideae $(n=1)$ were recovered, indicating that the plant species harvested or cut were from the members of the Poaceae, including Panicoideae, Bambusoideae and other plants. This result was similar to the results of the previous study on two perforated shells28.

The other functions: Although the functions of harvesting and cutting are inferred, we cannot be certain these functions are principal because the inference is based on an extremely small number of starch grains and phytoliths (Table 1), and there are only three perforated shells are taken into account. We can still consider, however, the sources of the remaining starch and phytolith residues and the cause of scars and use wear. Scars and use wear explicitly demonstrate a utilitarian function, and we cannot rule out the possibility that plant residues on the shell backs are derived from the tool use as the manipulator's hands touched both the starchy foods and shells at the same time. The shells must have been surrounded by the foods as they were processed. This interpretation is further supported by previous studies that have demonstrated that few starches could be deposited on the artifacts from adjacents sediments $33,45,46$.

Taking all data into account, the recovered phytoliths are derived from stem/leaves, and the recovered starches are often from three groups, the members of Panicoideae, geophytes, and the tribe Triticeae. This generalization applies to both the Xianrendong and Dioatonghuan sites, and to the artifacts from both the late Paleolithic age and early Neolithic age (Fig. 3). These results suggest that the perforated shells were used to process grasses from the Panicoideae and the tribe Triticeae, or/and to dig or scrape roots and tubers continuously from the late Paleolithic to the Neolithic period.

Changes of plant subsistence with rice exploitation over time.During Phase 1, Phase 2 and Phase 3, the proportion of remains from the Panicoideae and the tribe Triticeae remains tends to be stable (Fig. 3 S-B, S-D), whereas the proportion of plants from acorns and geophytes changed from $0 \%$ to $19 \%$ (Fig. 3 S-A, SC). The numerous faunal remains from these phases are mainly from mammals at both sites. Deer dominate the assemblage, making up $87.2 \%$ of the identified specimens ( $n>1,700)$, followed by wild boar (Sus scrofa) $(6.2 \%, n>300) 10$. During the Phase 2 the double peaked phytoliths from the glumes of domesticated rice of sediments first appear, and they make up $7 \%$ of the assemblage (Fig. 3 RP)26. The combination of archaobotanical and zooarchaeological data indicate that occupants at the Xianrendong and Diaotonghuan sites collected and consumed a variety of wild plants and animals. This broad-spectrum subsistence strategy was practiced by the foraging groups during the Phase 1, Phase 2 and Phase 3 periods.

In Phases 4, 5 and 6, the proportion of tubers and roots increased over time (Fig. 3 S-C), whereas the proportion of grasses in the Panicoideae and Triticeae decreased (Fig. 3 S-B, S-D). It was also during the Phases 4, 5 and 6 that double peaked phytoliths of domesticated rice extracted from sediments increased over time from $44 \%$ to $57 \%$ of the entire phytolith assemblage26 (Fig. 3 Line RP). These patterns indicate that ancient humans began the concentrated utilization of certain plant resources such as roots and tubers, as well as the rice cultivation.

The domestication of both plants and animals began to appear worldwide at the turn of the late Paleolithic and early Neolithic periods47-51. With the development of cereal cultivation and harvesting techniques, diverse tools emerged to support farming activities. During the phase 6 , the stone tools excavated from the Xianrendong and Diaotonghuan sites changed from chopping and smashing tools to a combination dominated by chopping, cutting and grinding tools that were previously associated with plant cultivation by means of typology 10 . Also during phase 6 , rice phytoliths excavated from sediments with domesticated characteristics reach up to $57 \%$ at the Diaotonghuan site26. The increase of use of tubers and roots may indicate that the function of perforated shells of digging and scraping tubers and roots was enhanced in phase 6 . While we did not recover phytoliths and rice from the shells, our results can neither support nor refute the harvesting of rice. The starches from rice are tiny and too difficult to find and identify52 and characteristic phytoliths from rice are produced from husks and leaves resulting in the little chance to contact the harvesting tools.

\section{Conclusions}


Data derived from use traces, starch grains, and phytoliths indicate that the functions of perforated shells recovered from the Xianrendong and Diaotonghuan sites included processing grasses from the tribes of Panicoideae and Triticeae, acorns, or/and their starchy products, and digging and scraping tubers and roots between 30,000 cal. Y BP and 12,000 cal. Y BP. Between 20,000 cal. Y BP to 12,000 cal. Y BP, the digging and scraping of tubers and roots increased while the processing of grasses from the Panicoideae and the tribe Triticeae decreased. The evidence indicates that the major functions of shell tools from the two sites changed over time as subsistence strategies shifted from foraging to rice cultivation.

\section{Materials And Methods}

Materials. The Xianrendong site was discovered in the early 1960s, and excavation was immediately conducted in 1962. Three trenches (No. T1, T2, and T3) were completed during the first excavation season (Fig. 4A). The second excavation was conducted in 1964, and three more trenches (No. T4, T5, and T6) were dug (Fig. 4A). The third to five excavations were led by professor Wenming Yan from Peking University and Richard Stockton MacNeish, director of the Andover Archaeological Foundation of the United States during excavation seasons of 1993, 1995, and 1999. In total, four trenches in the eastern region (No. TE0N4, TE1N4, TE2N4, TE3N4) and six trenches in the western region (No. TE10N10, TE10N11, TE10N12, TE11N10, TE11N11, TE11N12) were excavated and systematically sampled (Fig. 4A, B). During the excavation season in 1993, the strata at the Xianrendong site were numbered based on the Chinese traditional way, i.e., the general layers were numbered according to the excavation sequence from the top to the bottom with circled Arabic numerals, and the sub-layers were numbered with uppercase English letters A, B, C, etc. after the circled Arabic numerals, sequentially (Fig. 4B). A total four general layers with thirteen sublayers were identified in the western region, and twenty-two sub-layers within the six general layers were differentiated in the eastern region. Four double-hole

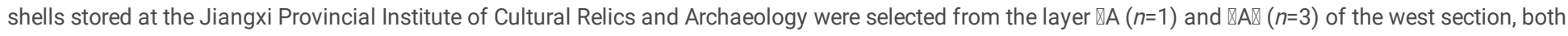
of which were sampled during the third excavation (Tables 1 and 2, Fig. 1B a-d).

The Diaotonghuan site was discovered in 1982, and excavated as the third excavation of the Xianrendong site. The method of numbering trenches was the same as the Xianrendong site, however, the stratigraphic numbers are based on the American numbering method. That is, both the general and the specific stratum are numbered in uppercase English letters from top to bottom (Fig. 5A). The stratigraphic numbers of this excavation were compiled from A to R (Fig. $5 B)$. Three intact and five broken single hole shells were selected from the first excavation, which had been stored at the Jiangxi Provincial Institute of Cultural Relics and Archaeology. Artifacts were from layers $\mathrm{E}(n=1), \mathrm{F}(n=2), \mathrm{G}(n=2), \mathrm{H}(n=2)$, and L $(n=1)$, respectively (Tables 1 and 2, Fig. 1B e-l).

According to the comprehensive study on stratigraphic accumulation patterns, the manufacturing technology of stone artifacts, and AMS dating, the Xianrendong and Diaotonghuan sites were occupied from 30,000 cal. Y BP to 12,000 cal. Y BP 10,27 . In addition, based on the sequence of the strata, the ages of the twelve perforated shells were also determined to be between 30,000 and 12,000 cal. Y BP, as shown in Table 2. Further, all twelve shells were identified from the species of Cristariaplicata ${ }^{10}$ (Fig. 2a, b), and were drilled holes in varied sizes (Table 1).

Methods. We completed microscopic observation of artifacts and our statistical analyses using a stereomicroscope (model: Nikon SMZ25), noting both starch and phytolith residues, or the absence thereof, on the used edges and unused backs of the twelve perforated shells. To control for possible modern contamination, we also collected and analyzed two dust samples from the storeroom where the shells were curated.

The use marks on the surface of perforated shells, including scratching, pitting, and glossing, were observed under a stereomicroscope (model: Nikon SMZ25) with a magnification of 150x. Further, the observed use marks were compared with those produced in simulation experiments using modern shell or stone tools to cut and grind bovid bones, grasses from millets and reeds (Phragmites) ${ }^{14,22,23}$.

The used edges and unused backs of shells were cleaned independently of one another in an ultrasonic bath to extract starches for 10 min, after which a solution of $6 \% \mathrm{H}_{2} \mathrm{O}_{2}$ was used to remove the organic matter from the samples ( $30 \mathrm{~min}$ ). Next, a heavy liquid (using a solution of $\mathrm{CsCl}$, density, $1.8 \mathrm{~g} / \mathrm{cm}^{3}$ ) was used to float starches. Finally, after washing the heavy liquid, slides were prepared, observed under a microscope with polarized and unpolarized light, respectively (Machine model: Nikon SMZ25), then photographed, identified, and quantitative analyses were conducted.

Phytoliths from the surface residues of the perforated shells were extracted from the solution remaining after the extraction of the starches. A heavy-liquid of $\mathrm{ZnBr}_{2}$ at the density of $2.3 \mathrm{~g} / \mathrm{cm}^{3}$ was used for flotation, and residual phytoliths were obtained and prepared. Finally, they were observed under a microscope, were identified, and were subjected to statistical analyses (Machine model: Zeiss Axio Scope A1).

For extracting starch grains and phytoliths from dust samples, $0.5 \mathrm{~g}$ of each dust sample was subsampled and $6 \% \mathrm{H}_{2} \mathrm{O}_{2}$ was added to remove the organic matter. Thereafter, a solution of $10 \% \mathrm{HCl}$ was used to remove calcium impurities. Next, the resulting sediment was mixed with a $5 \%$ solution of sodium hexametaphosphate (Calgon) to deflocculate clay minerals and ease the dispersal of sediment samples. At this point the heavy liquid (using a solution of $\mathrm{CsCl}$, density, $1.8 \mathrm{~g} / \mathrm{cm}^{3}$ ) flotation method was conducted; the bottom residue sample left after the flotation of the starch grains was subjected to a secondary flotation using $2.3 \mathrm{~g} / \mathrm{cm}^{3}$ of $\mathrm{ZnBr}_{2}$ heavy liquid to obtain a phytolith residue, which was observed under a microscope (Machine model: Zeiss Axio Scope A1).

The observation and analysis of use wear marks on the perforated shells were conducted at the Paleoethnobotany and Zooarchaeology Laboratory in Northwest University. The analyses of the starch grains and phytoliths were performed at the environmental archaeology lab of the Institute of Geographic Sciences and Natural Resources Research, Chinese Academy of Sciences. The identification of ancient starches and phytoliths recovered from the surface residue of perforated shells was based on one-on-one comparisons with those from over 200 Asian species housed in our modern collections, including 50 genera from the Poaceae, Leguminosae, and Fagaceae, and also from published images and data ${ }^{32,36-38}$.

\section{Declarations}


This work was supported by the National Natural Science Foundation of China (41807436 and 41771231).

\section{Author Contributions}

X.Y. and Z.M. designed research, and also performed the analytical model. Z.M. was responsible for the paper writing process, wrote large parts of the paper, and led the development of the framework as well as the data analysis. X.Y. and C.Z. Responsible for project management. Z.M., C.Z., X.H., Z.W., G.Z. and X.Y. Provided resources; Z.M., L.P., Y.M. and C.Z. analyzed data. Z.M., Y.M. and S.L. wrote the original draft of the paper. X.Y. and L.P. reviewed and edited the paper. All authors reviewed the manuscript.

Competing Interests: The authors declare no competing interests.

\section{References}

1. Wang, R. The study of Neolithic shell tools from China. Nongye kaogu (Agric. Archaeol.), 1, 145-155 (in Chinese) (1987).

2. Xu, L. The study of bones, ivories and shells from ancient China. Wen Bo (Relics Museol.), 1, 7-16 (in Chinese) (1994).

3. Douka, K. An Upper Palaeolithic shell scraper from KsarAkil (Lebanon). Archaeol. Sci.38, 429-437 (2011).

4. Joordens, J.C. et al. Homo erectus at Trinil on Java used shells for tool production and engraving. Nature.518, 228-231(2015).

5. Szabó, K., Brumm, A. \& Bellwood, Shell artefact production at 32,000-28,000 BP in Island Southeast Asia: thinking across media? Curr. Anthropol.48, 701723 (2007).Szabo K,

6. Huang, W. et al. Bone artifacts and ornaments from Xiaogushan Site of Haicheng, Liaoning province. Acta Anthropol. Sin.5, 259-267 (in Chinese) (1986).

7. Huang, W., Ji, H. \&Lin, Y. A late Paleolithic shell tool from Xinjiang, Shanxi. Acta Anthropol. Sin.5, 267-270 (in Chinese) (1986).

8. Song, Y. \& Shi, J. A brief report on the excavation of Shizitan S29 site in Jixian country, Shanxi Province. kaogu (Archaeology).2, 35-51 (in Chinese) (2017).

9. Zhang, J. et al. The paleolithic site of Longwangchan in the middle Yellow River, China: chronology, paleoenvironment and implications. Archaeol. Sci.38, 1537-1550 (2011).

10. SAM PK (School of Archaeology and Museology. Peking University). \& JPICRA (Jiangxi Provincial Institute of Cultural Relics and Archaeology). Xianrendong and Diaotonghuan sites (Cultural Relics Publishing House, Beijing, 2014) (in Chinese).

11. Jiang, Y. The study of Bailiandong site, Miaoyan site and Xianrendong site: typical cases at the transition from the Paleolithic to the Neolithic period in South China. Shiqian yanjiu (Prehistory).1, 58-67 (in Chinese) (2006).

12. Li, L. Research of shell tools in Chinese prehistoric (Shanxi University, 2015) (in Chinese).

13. Zhang, S. Mussel sickle-the name of perforated mussel tools and its utility in Zengpiyan site. Shiqian yanjiu (Prehistoric).1, 245-250 (in Chinese) (2010). 14. Douka, K. \& Spinapolice, E.E. Neanderthal Shell Tool Production: Evidence from Middle Palaeolithic Italy and Greece. World Prehist.25, 45-79 (2012).

15. Chen, G. \& Zhang, D. Marks on the clams of the Xinglongwa culture. Beifang wenwu (North. Cult. Relics).3, 8-11 (in Chinese) (2012).

16. Qin, J. Clam spoon and shell ritual article. Relics.2, 27-28 (in Chinese) (1983).

17. Zhang, D. Research on Neolithic calm-device of ancient-Liaoxi region (Shanxi University, 2014) (in Chinese).

18. Rao, H. et al. Earliest use of birch bark tar in Northwest China: evidence from organic residues in prehistoric pottery at the Changning site. Hist. Archaeobot. 28, 199-207 (2019).

19. Mcgovern, P. E. et al. Fermented beverages of pre-and proto-historic China. Natl. Acad. Sci. USA.101, 17593-17598 (2004).

20. Yang, X. et al. Experiments with lithic tools: understanding starch residues from crop harvesting. 56, 828-840 (2014).

21. Ma, Z. et al. Plant microremains provide direct evidence for the functions of stone knives from the Lajia site, northwestern China. Bull.59, 1151-1158 (2014).

22. Liu, L., Wang, J. \& Levin, M. J. Usewear and residue analyses of experimental harvesting stone tools for archaeological research. Archaeol. Sci. Rep.14, 439-453 (2017).

23. Choi, K. \& Driwantoro, D. Shell tool use by early members of Homo erectus in Sangiran, central Java, Indonesia: cut mark evidence. Archaeol. Sci.34, 4858 (2007).

24. Allen, M. \& Ussher, E. Starch analysis reveals prehistoric plant translocations and shell tool use, Marquesas Islands, Polynesia. J. Archaeol. Sci.40, 27992812 (2013).

25. Barton, H. Starch residues on museum artefacts: implications for determining tool use. Archaeol Sci.34, 1752-1762 (2007).

26. Zhao, Z. The Middle Yangtze region in China is one place where rice was domesticated: phytolith evidence from the Diaotonghuan Cave, Northern Jiangxi. 72, 885-897(1998).

27. Wu , X. et al. Early pottery at 20,000 years ago in Xianrendong Cave, China. 336, 1696-1700 (2012).

28. Wan, Z. et al. Starch residues from sites of Xianrendong and Diaotonghuan and its implications for paleoclimate. Res. 32, 256-263 (in Chinese) (2012).

29. Zhang, C. The discovery of early pottery in China. Praehist.29, 29-35 (2002).

30. Wet, J. M. \& Huckabay, J. P. The origin of sorghum bicolor. \. Distribution and domestication. 21, 787-802 (1967).

31. Galinat, W. C. The origin of maize. Rev. Genet.5, 447-478 (1971). 
32. Liu, L. et al. Plant exploitation of the last foragers at Shizitan in the Middle Yellow River Valley China: evidence from grinding stones. Archaeol. Sci. 38, 3524-3532 (2011).

33. Yang, X. et al. Early millet use in northern China. Natl. Acad. Sci. USA. 109, 3726-3730 (2012).

34. Yang, X. et al. From the modern to the archaeological: starch grains from millets and their wild relatives in China. Archaeol. Sci.39, 247-254 (2012).

35. Liu, L., Ma, S. \& Cui, J. Identification of starch granules using a two-step identification method. Archaeol. Sci.52, 421-427 (2014).

36. Wang, W. et al. Morphological analysis of modern starch grains of underground storage orangs in China. Sci.38, 1409-1423 (in Chinese) (2018).

37. Yang, X. \& Perry, L. Identification of ancient starch grains from the tribe Triticeae in the North China Plain. Archaeol. Sci.40, 3170-3177 (2013).

38. Lu, H. et al. Phytoliths analysis for the discrimination of foxtail millet (Setaria italica) and common millet (Panicum miliaceum). PLoS One.4, e4448 (2009).

39. Wang, Y. \& Lu, H. Phytolith study and its application (China Ocean Publishing, Beijing, 1993) (in Chinese).

40. Lu, H. et al. Phytoliths as quantitative indicators for the reconstruction of past environmental conditions in China I: phytolith-based transfer functions. Sci. Rev. 25, 945-959 (2006).

41. Ge, Y. et al. Phytolith analysis for the identification of barnyard millet (Echinochloa sp.) and its implications. Anthropol. Sci.10, 61-73 (2016).

42. Li, Q., Xu, D. \& Lu, H. Morphology of phytolith in Bambudoideae (gramineae) and its ecological significance. Res. 25, 777-784 (in Chinese) (2005).

43. Barton, H. \& White, J. Use of stone and shell artifacts at Balof 2, New Ireland, Papua New Guinea. Asian Perspect.32, 169-181 (1993).

44. Shen, C \& Chen, C. The exploration and practice of use-wear: a case study for the stone artifacts in Xiaochangliang site. 7, 62-73 (in Chinese) (2001).

45. Li, M. et al. Ancient starch grains from ash pits of Fengtai site, Qinghai Province and their application in archaeology. Res. 30, $372-376$ (in Chinese)

46. Ma, Z. et al. Understanding the possible contamination of ancient starch residues by adjacent sediments and modern plants. 9, 752e $(2017)$.

47. Crawford, G. W. \& Shen, C. The origins of rice agriculture: recent progress in East Asia. 72, 858-866 (1998).

48. Bellwood, P. First Farmers: The Origins of Agricultural Societies (Blackwell Publishing, London, 2005).

49. Crawford, G. East Asian Plant Domestication (Blackwell Publishing, London, 2008).

50. Cohen, D. The beginnings of agriculture in China: A multiregional view. Anthropol. 52,S273-S293 (2011).

51. Fuller, D. et al. Convergent evolution and parallelism in plant domestication revealed by an expanding archaeological record. Natl. Acad. Sci. USA.111, 6147-6152 (2014).

52. Li, W. et al. The influence of grinding on the preservation of starch grains from rice. $62, \mathbf{1 5 7 - 1 7 1}$ (2020).

\section{Tables}

Table 1. Samples from the Xianrendong and Diaotonghuan sites, and the number and classification of starch grains and phytoliths recovered from surface residues $^{\text {a) }}$ 


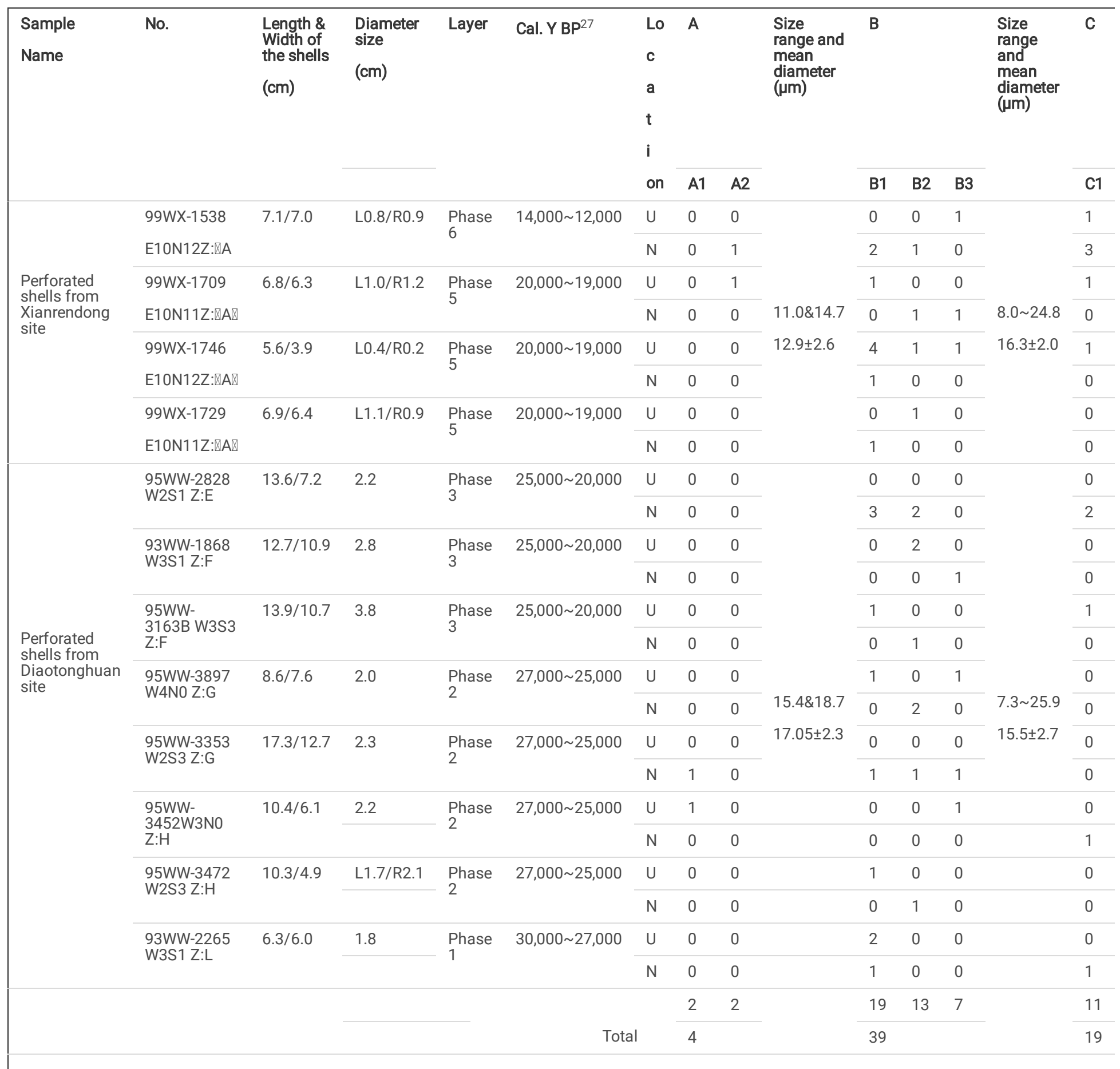

Note: a) The sampling position $U$ represents the used edges of the twelve perforated shells, and $\mathrm{N}$ represents the unused backs of the twelve perforated shells. Different alphabetic codes represent different types of micro remains. A, type A starches from acorns; $B$, type B starches from Panicoideae; C, type C starches from roots and tubers; D, type D starches from the tribe Triticeae; E, type of E starches (unidentifiable); F, Smooth elongate phytolith from the Poaceae; G, Acicular hair cell from the Poaceae; $\mathrm{H}$, Long-saddle phytolith from the Bambusoideae; I, Bilobate phytolith from the Panicoideae; J, Square phytolith from the Poaceae.

Table 2. The age of each stratigraphic layer at the Xianrendong and Diaotonghuan Sites 


\begin{tabular}{|c|c|c|c|c|}
\hline \multirow[t]{2}{*}{ Layer } & Xianrendong Site & Diaotonghuan Site & Age (Cal. Y BP) & \multirow[b]{2}{*}{ No. of sampled shell remains } \\
\hline & Eastern Region & & & \\
\hline Phase 1 & $\triangle A, \otimes B, \nabla C$ & $\mathrm{~K}-\mathrm{R}$ & $30,000-27,000$ & 1 \\
\hline Phase 2 & 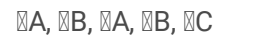 & G-J & $27,000-25,000$ & 4 \\
\hline Phase 3 & $\triangle A, \triangle A \otimes, \otimes B$ & $E, F$ & $25,000-20,000$ & 3 \\
\hline Phase 4 & $\triangle \mathrm{B}, \triangle \mathrm{B} \otimes, \mathrm{QB} \bigotimes$ & $\mathrm{D}$ & $20,000-19,000$ & 0 \\
\hline Phase 5 & Fea.2, $₫ A \rrbracket, \nabla A \rrbracket, \nabla A \rrbracket$ & $\mathrm{D}$ & $20,000-19,000$ & 3 \\
\hline Phase 6 & $\bigotimes A$ & & $14,000-12,000$ & 1 \\
\hline
\end{tabular}

\section{Figures}

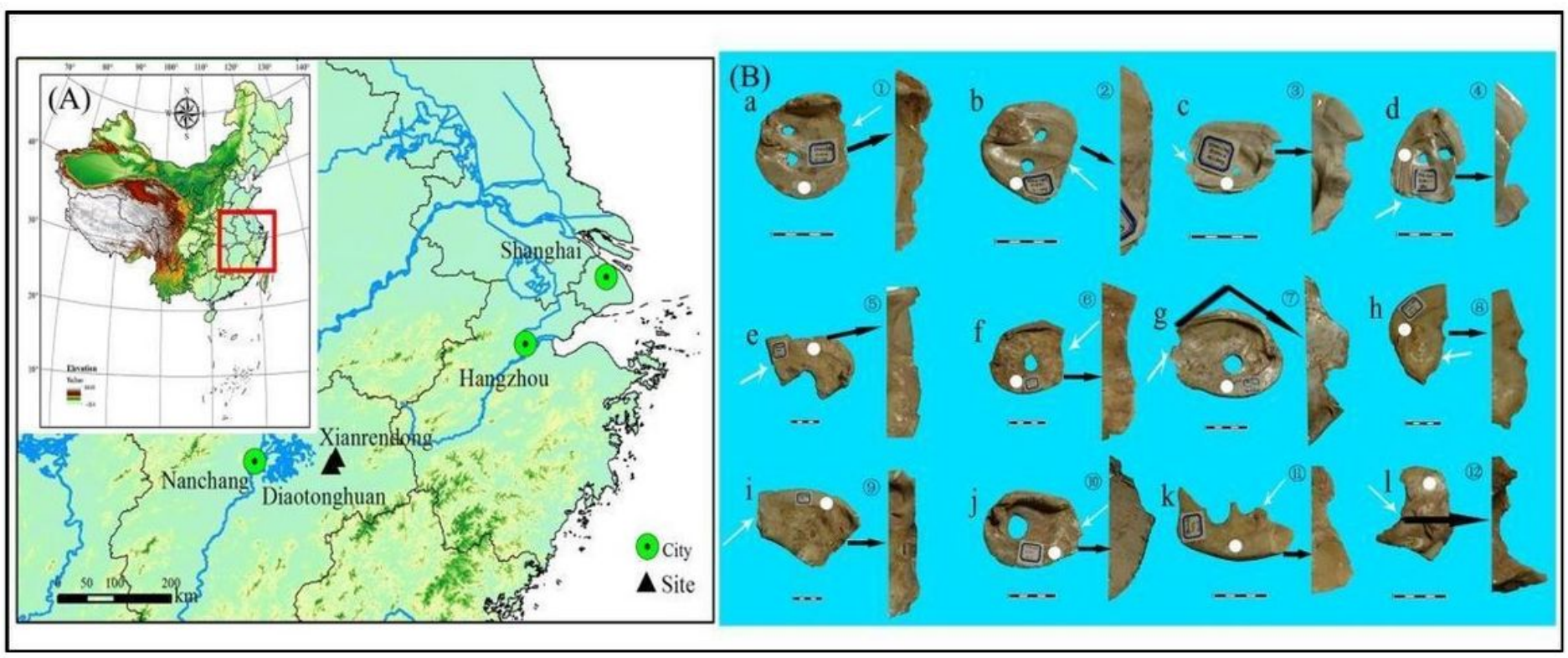

Figure 1

Locations of the Xianrendong and Diaotonghuan sites and the twelve perforated shells analyzed in this study A: Location of the Xianrendong and Diaotonghuan sites, B: (a-l) twelve perforated shells, ( $(-\mathbb{Z})$ collapse scar. White dots and arrows indicate the sampling locations and black arrows represent the collapse scar. Scale bar: $5 \mathrm{~cm}$. Note: The designations employed and the presentation of the material on this map do not imply the expression of any opinion whatsoever on the part of Research Square concerning the legal status of any country, territory, city or area or of its authorities, or concerning the delimitation of its frontiers or boundaries. This map has been provided by the authors. 


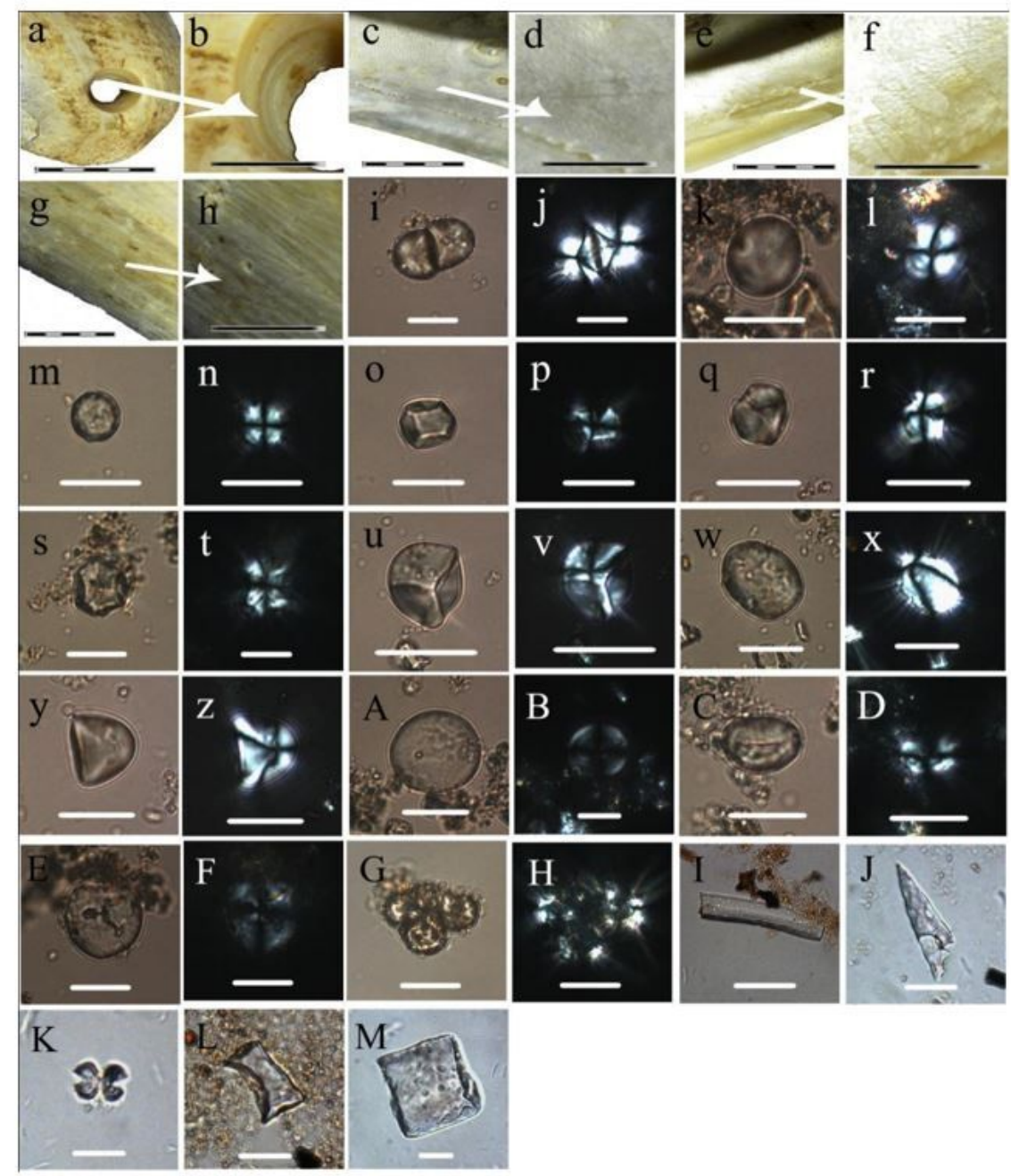

Figure 2

Usage traces, ancient starch grains and phytoliths on the perforated shells from the Xianrendong and Diaotonghuan site Usage traces: (a, b) perforate hole, (c, d) oblique trace, $(e, f)$ transverse trace, $(g, h)$ oblique trace. Starch grains: (i-l) Type A starch grains, (m-t) Type B starch grains, (u-z) Type C starch grains, (A-F) Type D starch grains, $(G, H)$ Type E starch grains. Phytolith: (I) smooth elongate, (J) acicular hair cell, (K) bilobate, (L) long-saddle, (M) square. Scale bar: a, c, e, g, $5 \mathrm{~cm} ; \mathrm{b}, \mathrm{d}, \mathrm{f}, \mathrm{h} 1 \mathrm{~cm} ; \mathrm{i}-\mathrm{M}, 20 \mu \mathrm{m}$. 


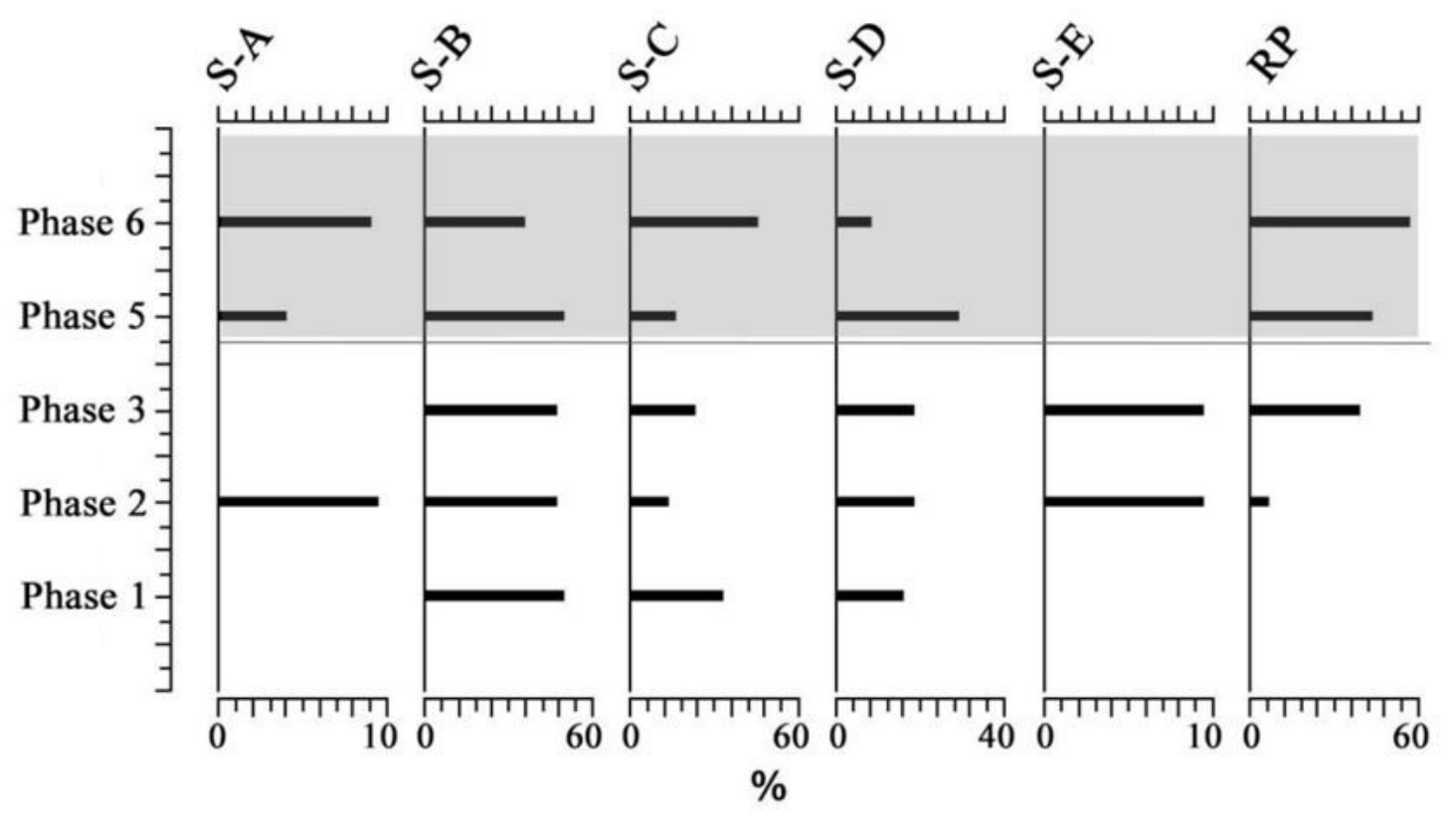

Figure 3

Percentage changes of starch grains and rice phytoliths over time at the Xianrendong and Diaotonghuan sites S-A, type A of starches from acorns; S-B, type B starches from Panicoideae; S-C, type $C$ of starches from roots and tubers; S-D, type D of starches from the tribe Triticeae; S-E, type of E starches from unidentifiable; RP, double peaked phytoliths from glume of domesticated rice26.

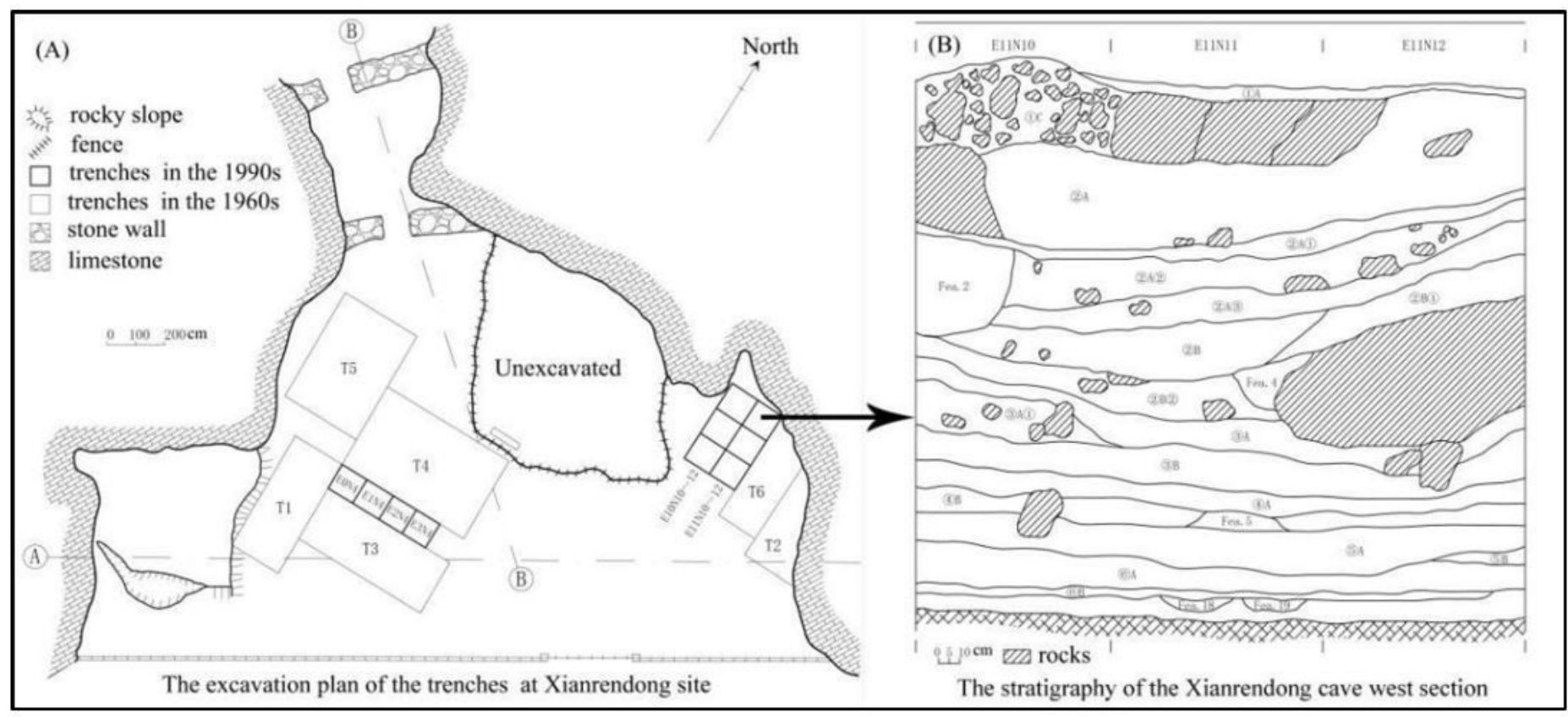

Figure 4

The excavation plan of the trenches and the representative stratigraphic profile at the Xianrendong site. A: The excavation plan of the trenches at the Xianrendong site, B: The strata of the Xianrendong Cave in the west section (Trenches: E11N10-E11N12)10. Note: The designations employed and the presentation of the material on this map do not imply the expression of any opinion whatsoever on the part of Research Square concerning the legal status of any country, territory, city or area or of its authorities, or concerning the delimitation of its frontiers or boundaries. This map has been provided by the authors. 


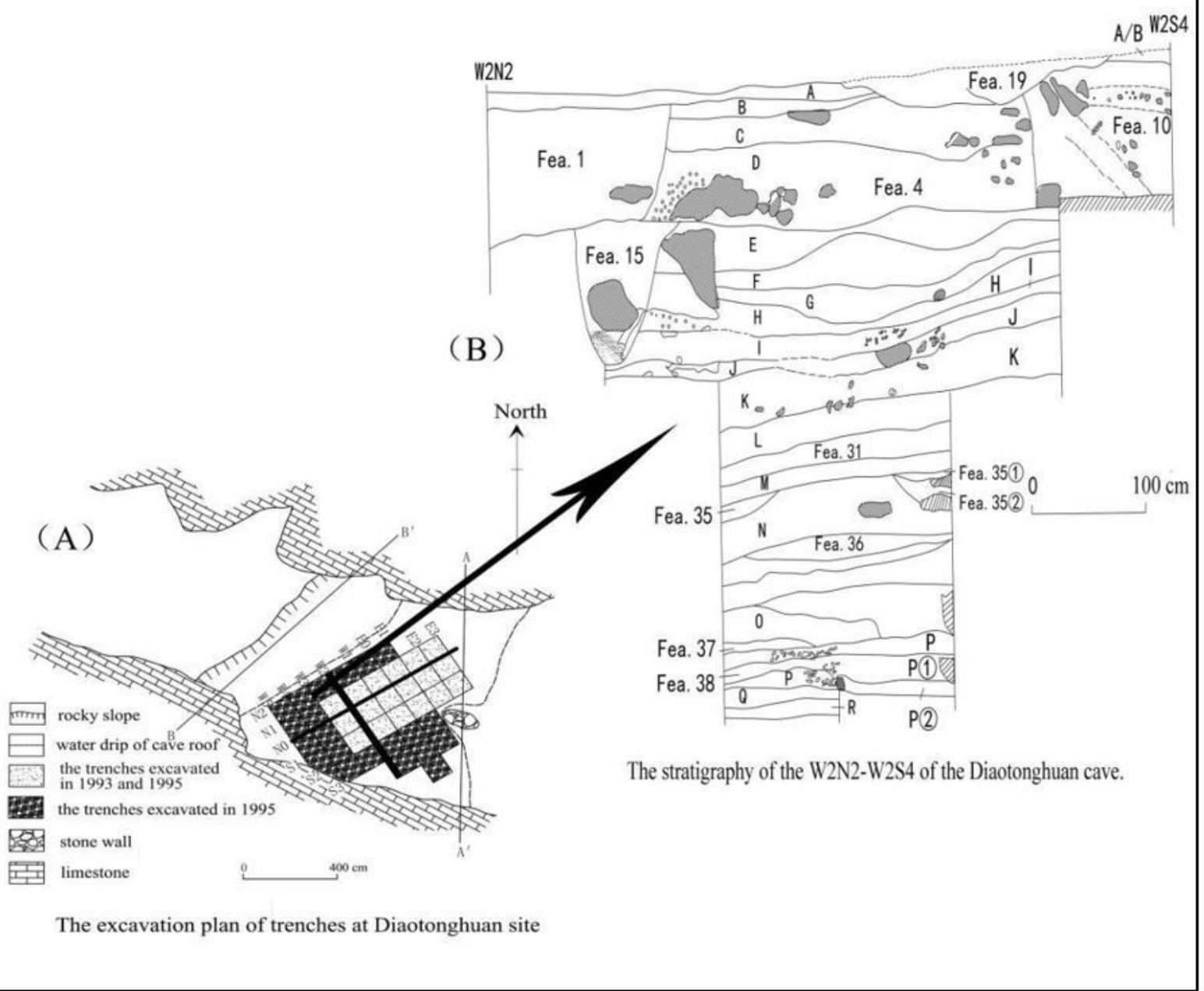

\section{Figure 5}

The excavation plan of the trenches and the representative stratigraphic section at the Diaotonghuan site. A: The excavation plan of the trenches at the Diaotonghuan site, B: The stratigraphy of the W2N2-W2S4 region of the Diaotonghuan cave10. Note: The designations employed and the presentation of the material on this map do not imply the expression of any opinion whatsoever on the part of Research Square concerning the legal status of any country, territory, city or area or of its authorities, or concerning the delimitation of its frontiers or boundaries. This map has been provided by the authors. 